\title{
Determination of hydraulic resistance of the aerothermopressor for gas turbine cyclic air cooling
}

\author{
Dmytro Konovalov ${ }^{l}$, Halina Kobalava ${ }^{l}$, Mykola Radchenko ${ }^{l}$, Ionut-Cristian $\mathrm{Scurtu}^{2}$, \\ Roman Radchenko ${ }^{l}$ \\ ${ }^{1}$ Admiral Makarov National University of Shipbuilding, Heroes of Ukraine Avenue, 9, \\ Mykolayiv, 54025, Ukraine \\ ${ }^{2}$. Mircea cel Batran Naval Academy, Romania
}

\begin{abstract}
One of the promising trends to increase the fuel and energy efficiency of gas turbines is contact cooling of cyclic air by using a twophase jet apparatus - an aerothermopressor. The rational parameters of work processes of the aerothermopressor were studied. The experimental setup was designed to simulate the aerothermopressor operation in the cooling air cycle of the gas turbine and to determine pressure losses in the aerothermopressor flow part. Based on the obtained experimental data, an empirical equation was proposed to determine the hydraulic resistance coefficient of the aerothermopressor flow part, depending on the initial pressure and the amount of water injected. The deviation of the calculated hydraulic resistance coefficient from the experimental ones is $\pm 25 \%$. The obtained results can be used in the practice of designing the aerothermopressor for gas turbine cyclic air cooling.
\end{abstract}

\section{Introduction}

To bring the process of compressing air in gas turbine compressors closer to isothermal ones the complex schemes with cyclic air cooling are usually used $[1,2]$. It results in increasing the fuel and energy efficiency [3, 4]. One of the promising trends is contact cooling of cyclic air $[5,6]$. For this purpose the jet technologies can be used [7-10]. To provide efficient evaporative cooling of gas turbine cyclic air without total pressure loss the aerothermopressor are quite useful [11]. Due to evaporative cooling in the aerothermopressor, an effect of thermogasdynamic compression is taken place - gas pressure is increased in the process of instantaneous evaporation of water injected into the gas (air) flow accelerated to a speed close to sound [12,13]. An effective water dispersed atomization in the air flow occurs in the aerothermopressor. This ensures efficient evaporation of the water dispersed flow in the flow part of the gas turbine compressor bringing the compression process closer to isothermal.

*Corresponding author: nirad50@gmail.com 


\section{Literature Review}

The aerothermopressor allows to compensate the pressure loss and reduce the work of compression in the compressor and to increase the working fluid flow and, accordingly, the gas turbine power output [11]. In addition, the aerothermopressor is compact and structurally and technologically simple to manufacture in comparison with surface air coolers $[12,14,15]$.

The working processes in the aerothermopressor are considerably influenced by design factors. The total pressure of the gas flow in the aerothermopressor is significantly affected by pressure losses caused by hydraulic and local resistance in the aerothermopressor flow part (confuser, evaporation chamber and diffuser) [13, 16]. Therefore for designing the aerothermopressors it is important to determine the rational parameters of working processes in their flow part.

The operation of the aerothermopressor on the gas turbine exhaust gases was investigated in [12]. Data on the pressure loss caused by local and hydraulic resistance were obtained for the experimental aerothermopressor (gas flow rate $G_{\mathrm{g}}=11.5 \mathrm{~kg} / \mathrm{s}$ ). It was shown that the total pressure of compressed air and the work of compression correspondingly was decreased by approximately $14 \%$.

The pressure losses in the aerothermopressor flow part depend primarily on the operating mode nature. The process of accelerating the gas flow to a transonic speed (0.5$0.9 \mathrm{M}$ ) occurs in the confuser. To the inlet chamber, located before the confuser, liquid is supplied using a nozzle or other special devices $[12,16,17]$. In the evaporation section, these flows interact, and, as a result, droplets are accelerated, crushed, heated and evaporated, and gas is also cooled [13]. There are three main operating modes of the aerothermopressor $[12,13,17]$ :

1. The influence of the water droplets resistance prevails over the positive effect of evaporation and determines the gas flow behaviour. The Mach number is increased, the static pressure of the flow is decreased, and the water temperature has risen approaching the saturation temperature.

2. Water evaporation predominates. The Mach number is decreased, and the total and static pressure is increased.

3. Surface friction (in the first two modes was relatively insignificant) becomes the predominant factor. This mode is taken place when the liquid completely evaporates.

All three modes determine the effect of hydraulic resistance on pressure losses. One of the ways to increase the aerothermopressor efficiency is to increase the total pressure by reducing losses due to hydraulic resistance of the flow part. It might be achieved by providing liquid incomplete evaporation - dispersed mode. Incomplete evaporation should provide a greater pressure increase, due to a friction losses decrease in the two-phase flow and it should provide effective fine atomization of water, due to a drop reduction during partial evaporation.

It is known that pressure losses in the two-phase flow (liquid-gas) may be less than pressure losses in the single-phase flow (gas) $[18,19,20]$. When providing liquid injection through the nozzle in an amount more necessary for evaporation, mode 3 is absent (in this mode, surface friction of the single-phase flow predominates). It positively affects the increase in total flow pressure as a result of the thermogasdynamic effect.

To determine pressure losses in the aerothermopressor, classical methods are used. These techniques are based on the analytical determination of the local and friction resistance coefficients of each of the aerothermopressor elements [21, 22]. Pressure losses due to resistance (acceleration or deceleration of the droplet) can be determined by the aerodynamic resistance coefficient of the droplet in the flow $\zeta_{\mathrm{w}}$ in accordance with the 
technique proposed in [21]. Pressure losses in the evaporation chamber $\zeta_{\text {ch }}$ might be determined by the classical Blasius equation for flow in the channels [22] or by the Lockcart-Martinelli phases slip model $[19,20]$. To calculate losses from the total resistance for the confuser and diffuser are used equations for the local loss coefficients $\zeta_{c}, \zeta_{d}[22,23]$.

Thus, the general equation for determining pressure losses in the aerothermopressor:

$$
\Delta P_{\mathrm{r}}=\zeta_{\mathrm{ATP}} \cdot \frac{w_{\mathrm{air}}^{2} \cdot \rho_{\mathrm{air}}}{2},
$$

where $\zeta_{\text {ATP }}$ - total coefficient of hydraulic resistance in the aerothermopressor flow part; $w_{\text {air }}$ - average air velocity in the evaporation chamber; $\rho_{\text {air }}-$ air density.

The total coefficient of hydraulic resistance is determined by:

$$
\zeta_{\mathrm{ATP}}=\zeta_{\mathrm{w}}+\zeta_{\mathrm{c}}+\zeta_{\mathrm{d}}+\zeta_{\mathrm{ch}}
$$

The application of the indicated methods for calculating losses by the elements of the aerothermopressor flow part often gives incorrect results. First of all, it is due to the complexity of accounting for the operating modes of the flow in the aerothermopressor.

Even more difficult is to determinate the losses due to the resistance of the droplet [24] in the confuser and in the evaporation chamber initial part. This is due to the difficulty in determining the initial velocity of the droplet, its diameter, etc. It has been experimentally established that such losses can reach $10-20 \%[12,13]$, but there are no equations for the exact determination of such losses for the aerothermopressor.

Determination of pressure losses in the aerothermopressor flow part experimentally, taking into account water injection, will clarify the design methodology for such jet devices. This will provide an accurate determination of the aerothermopressor effective use as a part of the gas turbine for cooling cyclic air under various operating conditions, as well as in various climatic conditions.

\section{Research Methodology}

The installation of the aerothermopressor in the gas turbine cyclic air cooling system is proposed in accordance with the scheme (Fig. 1) [11]. This arrangement between the compressors will reduce the operation of the gas turbine high-pressure compressor due to lower initial temperature of the compression process. This will ensure isothermal compression during the evaporation of the finely dispersed mixture in the high-pressure compressor flow part [25].

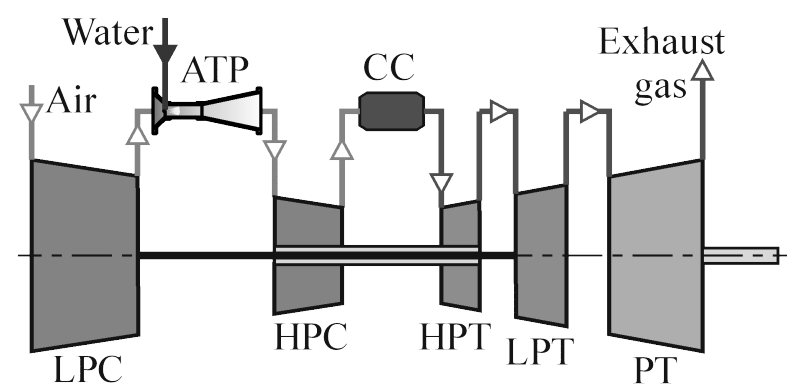

Fig. 1. Scheme of the gas turbine with cyclic air cooling by the aerothermopressor: ATP - aerothermopressor; LPC, HPC - low and high pressure compressors; CC combustion chamber; HPT, LPT - low and high pressure turbines; PT - power turbine.

To conduct an experimental study of determining pressure losses in the aerothermopressor flow part, an experimental setup was developed (Fig. 2). The 
experimental setup is designed to simulate the aerothermopressor operation in the cooling cycle air of the gas turbine.

The simulation of the aerothermopressor operation to cooling cyclic air of the gas turbine WR-21 from Rolls Royce $\left(N_{\mathrm{e}}=25.250 \mathrm{~kW}, g_{\mathrm{e}}=0.190 \mathrm{~kg} /(\mathrm{kW} \cdot \mathrm{h}), \eta_{\mathrm{e}}=41.2 \%\right)$ were considered.

The principle of experimental setup operation (Fig. 3): after cleaning in the air filter (2) (Caterpillar - 4N-0015 CAT), the air was supplied for compression to the screw compressor (3) (Atlas Copco XA 85), and pumped at $0.6 \mathrm{MPa}$ into the air receiver. After deep cleaning in the three-section moisture separator and oil separator (7), the air was heated in the ducted gas heater (11) to $t_{1}=50-180^{\circ} \mathrm{C}$. After preparation (approximation to gas turbine cyclic air parameters), the air entered into the experimental aerothermopressor (19). Water for injection came from a distilled water reserve tank (14) and it was injected by a highpressure pump (18) (STIHL RE 98). Water spray was carried out by nozzles of type FMT. At the pressure of $7.5 \mathrm{MPa}$, the nozzles provided a water flow rate at the receiving chamber inlet of the aerothermopressor: FMT-43.0 $-g_{\mathrm{w}}=0.0175 \mathrm{~kg} / \mathrm{s} ; \quad$ FMT-100.0 $g_{\mathrm{w}}=0.0407 \mathrm{~kg} / \mathrm{s} ;$ FMT $-120.0-g_{\mathrm{w}}=0.0487 \mathrm{~kg} / \mathrm{s}$. The spraying angle was $70-90^{\circ}$ and the average droplets diameter was $\delta_{\mathrm{w}}=18-20 \mu \mathrm{m}$ with a maximum diameter of $\delta_{\mathrm{w}}=50 \mu \mathrm{m}$.

The experimental aerothermopressor (Fig. 4 a) consists of the following elements: a receiving chamber with a nozzle (Fig. 4 b) and system for injecting water into the flow (Fig. 5 a); confuser (Fig. 5 b); evaporation chamber (Fig. 6 a); diffuser (Fig. 6 b); nozzles for installing temperature and pressure sensors. All elements of the aerothermopressor are removable allowed to carry out studies for the different geometric characteristics (Table 1).

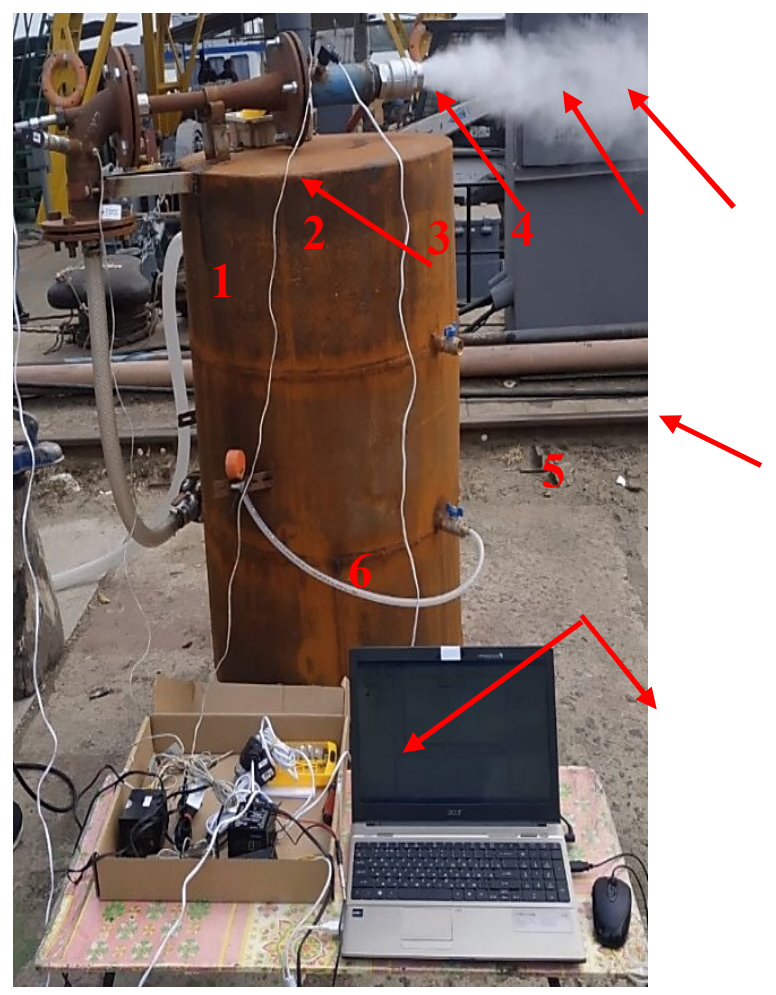

Fig. 2. Photo of the experimental setup:

1 - aerothermopressor receiving chamber with installed temperature and pressure sensors; 2 - aerothermopressor; 3 - pipe insert at the exit of the aerothermopressor with installed 
temperature and pressure sensors; 4 - control valve with a device for trapping droplets; 5 three-section moisture separator for air coming from the compressor module; 6 - computer monitoring and control system.

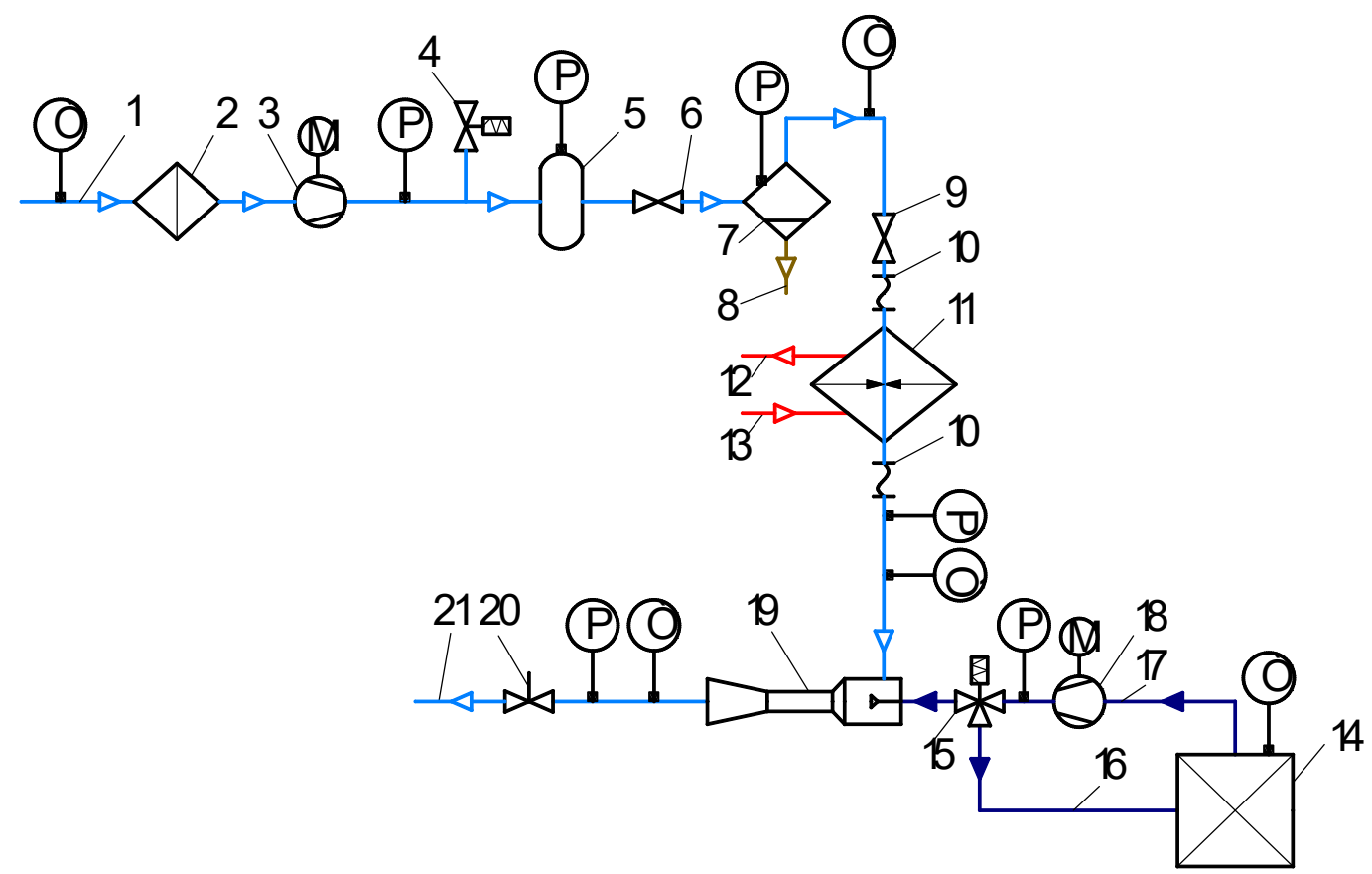

Fig. 3. Scheme of the experimental setup:

1 - inlet pipeline; 2 - air filter; 3 - screw compressor; 4 - safety valve; 5 - air receiver; 6,9

- control valves; 7 - three-section moisture separator; 8 - drain oil and moisture; 10 temperature compensator; 11 - gas air heater; 12, 13 - inlet and outlet of hot gas; 14 water reserve tank; 15 - control valve of the injection system; 16 - return pipeline; 17 pipeline for supplying water to the injection system; 18 - high pressure pump; 19 experimental aerothermopressor; 20 - control valve at the outlet; 21 - output pipeline; $\mathrm{P}$ pressure sensors; $\mathrm{T}$ - temperature sensors.

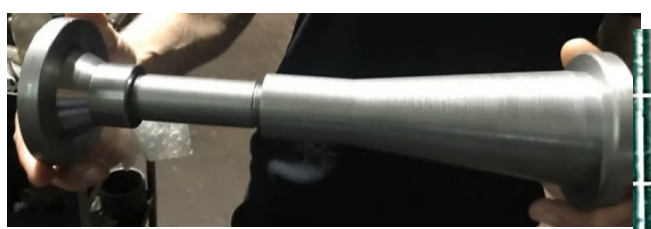

(a)

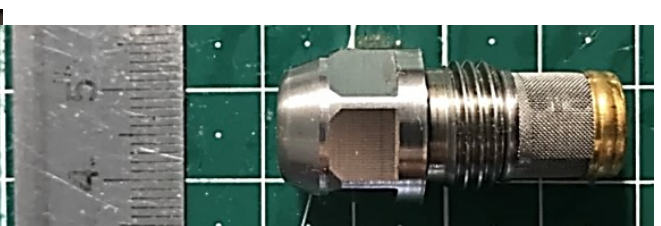

(b)

Fig. 4. Experimental aerothermopressor (a), a nozzle for water injection system (b). 


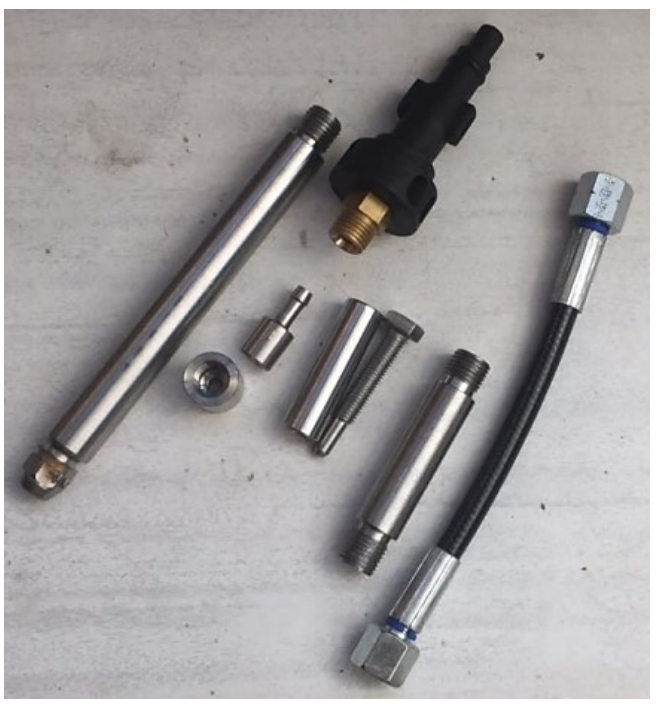

(a)

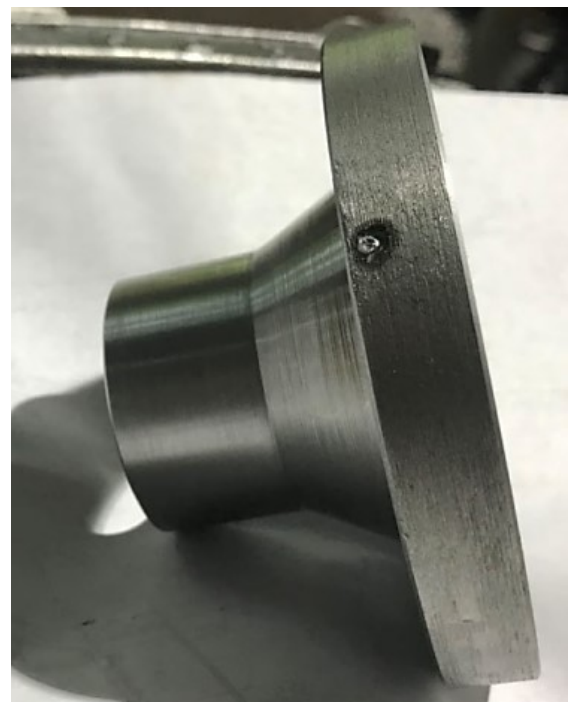

(b)

Fig. 5. Water injection system (a), confuser (b).

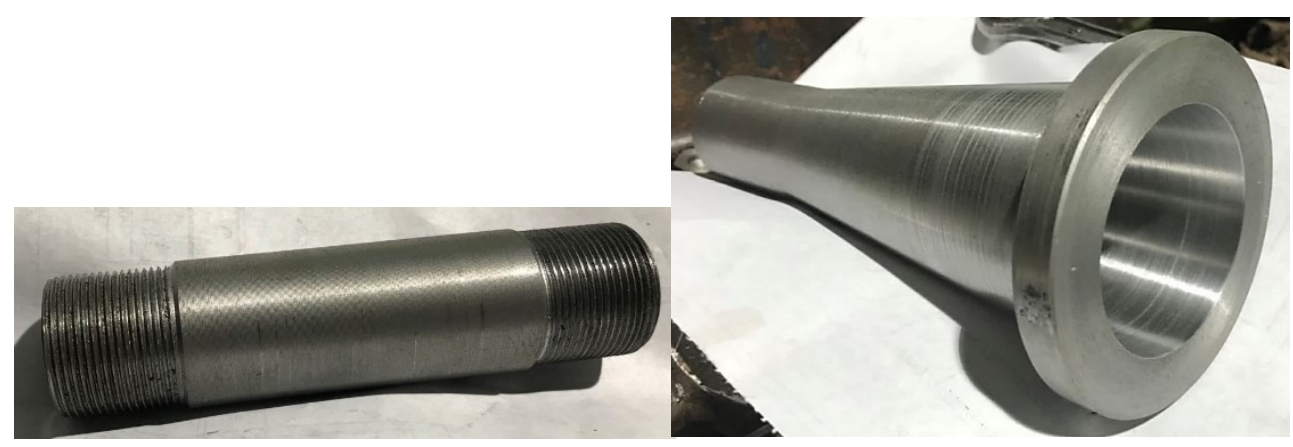

(a)

(b)

Fig. 6. Evaporation chamber (relative length $(L / D)=5)(\mathrm{a})$, diffuser (b).

All temperature, pressure and air flow sensors were connected to a developed computerized monitoring system. The parameters were measured with an interval $\tau=1 \mathrm{~s}$. To record the readings of measuring instruments, eight-channel meters I8-TS (temperature measurement) and I8-AT (pressure measurement) were used by RegMik. To collect and organize information about the data, a PI485 / USB RS485 communication interface converter was used, which converts USB interface signals (USB 1.1 and USB 2.0 compatibility) to RS485 / RS-422 / V.11 interface signals (EIA-485, EIA- 422A).

Testing and measuring devices with a list of the parameters they measure, the measurement range, accuracy classes and measurement errors are given in Table 2. The error of the experimental results was determined by the error of the measuring instruments, methodological and systematic errors.

To determine the local resistance coefficients for the diffuser and confuser, classical dependences of fluid dynamics [13, 14] were used. The energy equation (Bernoulli equation for air flow, taking into account mechanical specific losses): 


$$
\rho g z_{1}+p_{1}+N_{1} \frac{\rho w_{1}^{2}}{2}=\rho g z_{2}+p_{2}+N_{2} \frac{\rho w_{2}^{2}}{2}+\Delta p_{\mathrm{t}},
$$

where $\rho g z_{1}, \rho g z_{2}-$ geometric pressure; $p_{1}, p_{2}$ - static pressure; $\Delta p_{\mathrm{t}}-$ total losses of total pressure; $N_{1} \frac{\rho w_{1}^{2}}{2}, N_{2} \frac{\rho w_{2}^{2}}{2}-$ dynamic pressure.

Dividing by $\rho g$ :

$$
z_{1}+\frac{p_{1}}{g \rho}+N_{1} \frac{w_{1}^{2}}{2 g}=z_{2}+\frac{p_{2}}{g \rho}+N_{2} \frac{w_{2}^{2}}{2 g}+\Delta h_{\mathrm{t}},
$$

where $\Delta h_{\mathrm{t}}-$ total head losses.

The equation for total pressure is:

$$
p_{\mathrm{t}}=p_{1}+N_{1} \frac{\rho w_{1}^{2}}{2}
$$

Taking into account the fact that $z_{1}=z_{2}$ and Eq. (4), the total head losses $\Delta h_{\mathrm{t}}$ :

$$
\Delta h_{\mathrm{t}}=\frac{p_{\mathrm{t} 1}-p_{\mathrm{t} 2}}{g \rho}
$$

The local resistance coefficient $\zeta_{\mathrm{ATP}}$ is:

$$
\zeta_{\mathrm{ATP}}=\frac{2 \Delta p_{\mathrm{t}}}{\rho w^{2}}
$$

Table 1. Geometrical characteristics of the experimental aerothermopressor.

\begin{tabular}{ll}
\hline Parameter & Value \\
\hline Receiving chamber & Diameter $D_{1}=65 \mathrm{~mm}$; length $L_{1}=200 \mathrm{~mm}$ \\
\hline Confuser & $\begin{array}{l}\text { Inlet diameter } D_{\mathrm{c} 1}=65 \mathrm{~mm} \text {; outlet diameter } D_{\mathrm{c} 2}=25 \mathrm{~mm} ; \\
\text { length } L_{\mathrm{c}}=34 \mathrm{~mm} ; \text { convergent angle } \alpha=30^{\circ}\end{array}$ \\
\hline Evaporation chamber & $\begin{array}{l}\text { Diameter } D_{\mathrm{ch}}=25 \mathrm{~mm} \text {; length } L_{\mathrm{ch}}=125 ; 175 \mathrm{~mm} \\
\left.\text { (relative length } l_{\mathrm{ch}}=5 ; 7\right)\end{array}$ \\
\hline Diffuser & $\begin{array}{l}\text { Inlet diameter } D_{\mathrm{d} 1}=25 \mathrm{~mm} \text {; outlet diameter } D_{\mathrm{d} 2}=65 \mathrm{~mm} ; \\
\text { length } L_{\mathrm{ch}}=192 \mathrm{~mm} ; \text { divergent angle } \beta=66^{\circ}\end{array}$ \\
\hline Nozzle & $\begin{array}{l}\text { The distance between the water exit point to the receiving } \\
\text { chamber inlet: } L_{\mathrm{f}}=5 ; 65 ; 125 \mathrm{~mm}\left(L_{\mathrm{f}}=125 \mathrm{~mm} \text { corresponds to }\right. \\
\text { the evaporation chamber inlet) }\end{array}$ \\
\hline
\end{tabular}

Based on the obtained experimental data, for different values of the initial pressure at the aerothermopressor inlet $P_{1}$ and the relative amount of water injected $g_{\mathrm{w}}$, an empirical dependence was established by approximation to determine the pressure losses coefficient in the aerothermopressor with the flow rate to $0.52 \mathrm{~kg} / \mathrm{s}$.

The reliability of the work results is ensured by: the tasks correct formulation of the theoretical and experimental research; confirmation of the adequacy of the mathematical model with satisfactory agreement between the calculated and experimental data; using modern methods of experimental research and analytical modeling. 
Table 2. Testing and measuring devices.

\begin{tabular}{|c|c|c|c|}
\hline Measured value & $\begin{array}{l}\text { Name of measuring } \\
\text { instruments }\end{array}$ & Measuring range & Error \\
\hline Outside air temperature & \multirow{2}{*}{$\begin{array}{l}\text { Multifunction tester for } \\
\text { environment parameters } \\
1052 \text { (Chauvin Arnoux) }\end{array}$} & $-20 \ldots+80^{\circ} \mathrm{C}$ & $\pm 0.4 \%\left( \pm 0.3^{\circ} \mathrm{C}\right)$ \\
\hline Outside air pressure & & $0 \ldots 110 \mathrm{kPa}$ & $\pm 0.2 \%$ \\
\hline $\begin{array}{l}\text { Air pressure on the } \\
\text { discharge line, in front of } \\
\text { the "Cyclone" air separator }\end{array}$ & \multirow{4}{*}{$\begin{array}{l}\text { Measuring pressure } \\
\text { transducer, model A-10 } \\
\text { ("WIKA", Germany) }\end{array}$} & \multirow{4}{*}{$0 \ldots 600 \mathrm{kPa}$} & \multirow{4}{*}{ $\pm 0.14 \%$} \\
\hline $\begin{array}{l}\text { Air pressure in front of the } \\
\text { aerothermopressor }\end{array}$ & & & \\
\hline $\begin{array}{l}\text { Steam-water mixture } \\
\text { pressure in the evaporation } \\
\text { chamber of the } \\
\text { aerothermopressor }\end{array}$ & & & \\
\hline $\begin{array}{l}\text { Air pressure in the } \\
\text { discharge pipe of the } \\
\text { aerothermopressor }\end{array}$ & & & \\
\hline Discharge air temperature & \multirow{4}{*}{$\begin{array}{l}\text { Resistive temperature } \\
\text { transducer TSP-103 } \\
\text { ("RegMik", Ukraine) }\end{array}$} & \multirow{4}{*}{$-40 \ldots+270^{\circ} \mathrm{C}$} & \multirow{4}{*}{ $\pm 0.5 \%$} \\
\hline $\begin{array}{l}\text { Air temperature in front of } \\
\text { the aerothermopressor }\end{array}$ & & & \\
\hline $\begin{array}{l}\text { Steam-water mixture } \\
\text { temperature in the } \\
\text { evaporation chamber of the } \\
\text { aerothermopressor }\end{array}$ & & & \\
\hline $\begin{array}{l}\text { Air temperature in the dis- } \\
\text { charge pipe of the aero- } \\
\text { thermopressor }\end{array}$ & & & \\
\hline $\begin{array}{l}\text { Water pressure in the } \\
\text { system (in front of the } \\
\text { nozzle) }\end{array}$ & $\begin{array}{l}\text { Technical manometer } \\
\text { MT-UHL3 } \\
\text { (GOST 15150-82) }\end{array}$ & $0 \ldots 10 \mathrm{MPa}$ & $\pm 4 \%$ \\
\hline $\begin{array}{l}\text { Reserve tank water } \\
\text { temperature }\end{array}$ & $\begin{array}{l}\text { Resistive temperature } \\
\text { transducer TSP-103 } \\
\text { ("RegMik", Ukraine) }\end{array}$ & $-40 \ldots+270^{\circ} \mathrm{C}$ & $\pm 0.5 \%$ \\
\hline Air flow rate & $\begin{array}{l}\text { Variable area flow meter } \\
\text { type RM- } 25 \mathrm{GUZ}\end{array}$ & $0 \ldots 25 \mathrm{~m}^{3} / \mathrm{h}$ & $\pm 4.0 \%$ \\
\hline
\end{tabular}

\section{Results}

To determine the hydraulic resistance coefficient of the aerothermopressor flow part, a number of experimental measurements of pressure losses $\Delta P_{\mathrm{r}}$ were carried out under various conditions (Fig. 7, 8): the pressure at the inlet to the receiving chamber $-P_{1}=150$; $200 ; 250 ; 300 \mathrm{kPa}$; injected water flow rate relative to the flow rate of the two-phase flow $g_{\mathrm{w}}=5-35 \%$ (up to $0.0487 \mathrm{~kg} / \mathrm{s}$ ). The measurements are showed: at the inlet pressure $P_{1}=$ $300 \mathrm{kPa}$ pressure losses are $\Delta P_{\mathrm{r}}=55-75 \mathrm{kPa}(20-24 \%)$, at $P_{1}=250 \mathrm{kPa}$ pressure losses are $\Delta P_{\mathrm{r}}=40-45 \mathrm{kPa}(16-18 \%)$, at $P_{1}=200 \mathrm{kPa}$ pressure losses are $\Delta P_{\mathrm{r}}=22-24 \mathrm{kPa}(12-16 \%)$. In this case, with an increase in water flow rate $g_{\mathrm{w}}$, pressure losses increase by $2-4 \%$, and when the initial pressure decreases from 300 to $150 \mathrm{kPa}$, the effect of the amount of injected water gradually decreases. At $P_{1}=150 \mathrm{kPa}$, pressure losses are $\Delta P_{\mathrm{r}}=18-20 \mathrm{kPa}$ $(11-12 \%)$, but with an increase $g_{\mathrm{w}}$ to $35 \%$ pressure losses remain practically unchanged, the effect of water flow rate on pressure losses ceases. 
Pressure losses increase $\Delta P_{\mathrm{r}}$ with injected water flow rate increase $g_{\mathrm{w}}$ at inlet pressures $P_{1}=200-300 \mathrm{kPa}$ is explained by the greater difference between the initial droplet velocity at the nozzle exit and the air velocity $-\left(w_{\mathrm{w}} / w_{\mathrm{air}}\right)=1.1-1.3$. Hence, there is a greater influence of the droplet resistance. It can reach up to $20 \%$ of the total pressure loss in the aerothermopressor. At the pressure $P_{1}=150 \mathrm{kPa}$, the droplet and air velocities are almost equalized and the droplet resistance decreases significantly.

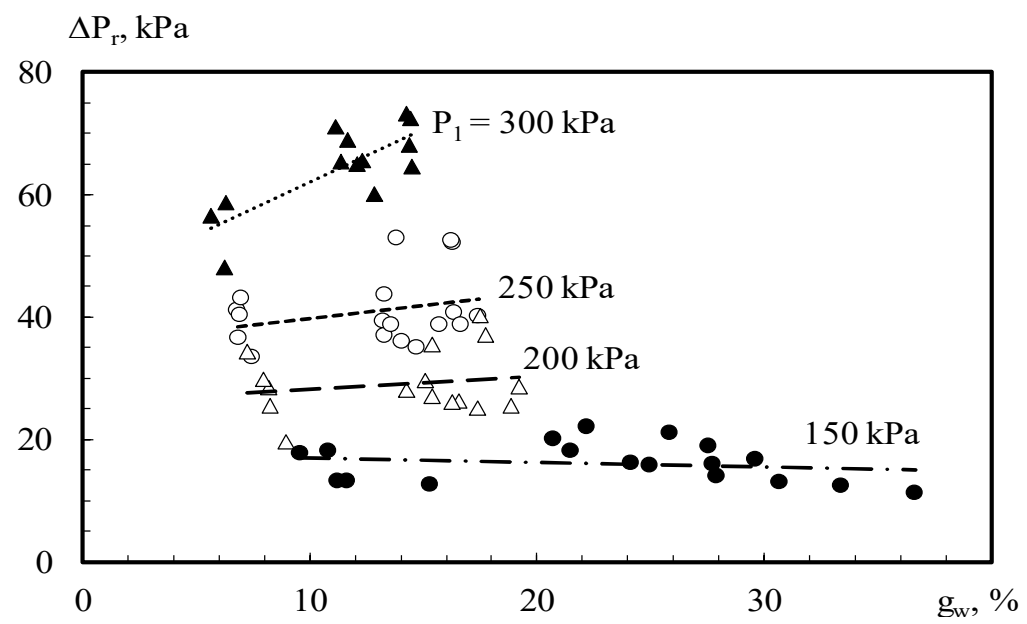

Fig. 7. Experimental dependences of pressure losses $\Delta P_{\mathrm{r}}$ on the relative flow rate of the injected water $g_{\mathrm{w}}$ at various initial pressures: $P_{1}=150 ; 200 ; 250 ; 300 \mathrm{kPa}$

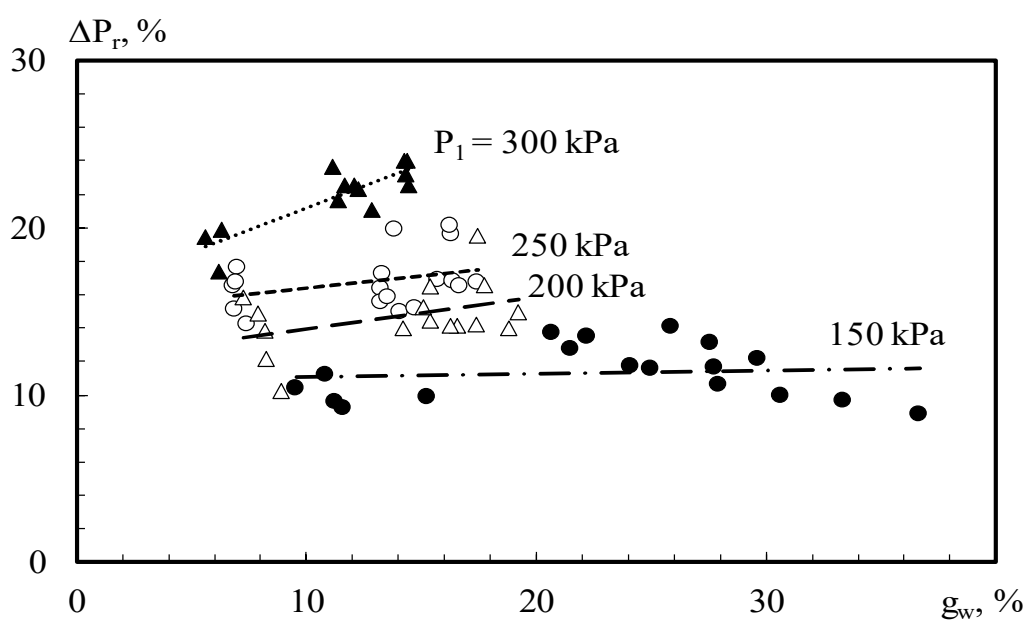

Fig. 8. Experimental dependences of pressure losses $\Delta P_{\mathrm{r}}=100 \cdot\left(P_{1}-P_{2}\right) / P_{1}(\%)$ on the relative flow rate of the injected water $g_{\mathrm{w}}$ at various initial pressures: $P_{1}=150 ; 200 ; 250$; $300 \mathrm{kPa}$.

Determination of the hydraulic resistance coefficient $\zeta_{\text {ATP.E }}$ for the aerothermopressor based on the data (Fig. 7, 8, 9): at $P_{1}=300 \mathrm{kPa}-\zeta_{\text {ATP.E }}=1.15-1.30$, at $P_{1}=250 \mathrm{kPa}-$ $\zeta_{\text {ATP.E }}=0.90-1.00$ and at $P_{1}=200 \mathrm{kPa}-\zeta_{\text {ATP.E }}=0.70-0.75$. The tendency of the hydraulic resistance coefficient behavior is the same as for absolute pressure losses $\Delta P_{\mathrm{r}}$, that is, with a water flow rate increase, the hydraulic resistance coefficient $\zeta_{\text {ATP.E }}$ increases by $0.05-0.15$. 
At $P_{1}=150 \mathrm{kPa}$ - the value of $\zeta_{\text {ATP.E }}$ practically does not change and it is $-0.35-0.40$. This behavior is explained by the fact that there are no influences of the $R e$ and the relative velocity $M=\left(w_{\text {air }} / w_{\text {sound }}\right)$ on the hydraulic resistance coefficient. This indicates there is a self-similar flow regime in the elements of the aerothermopressor flow part. The value of the hydraulic resistance coefficient depends only on the geometric parameters of the channel: confuser convergent angle $\alpha$ and diffuser divergent angle $\beta$; the degree of narrowing of confuser $n_{\mathrm{c}}$, the degree expansion of diffuser $n_{\mathrm{d}}$; the relative length of the evaporation chamber (caliber) $l_{\mathrm{ch}}=\left(L_{\mathrm{ch}} / D_{\mathrm{ch}}\right)$.

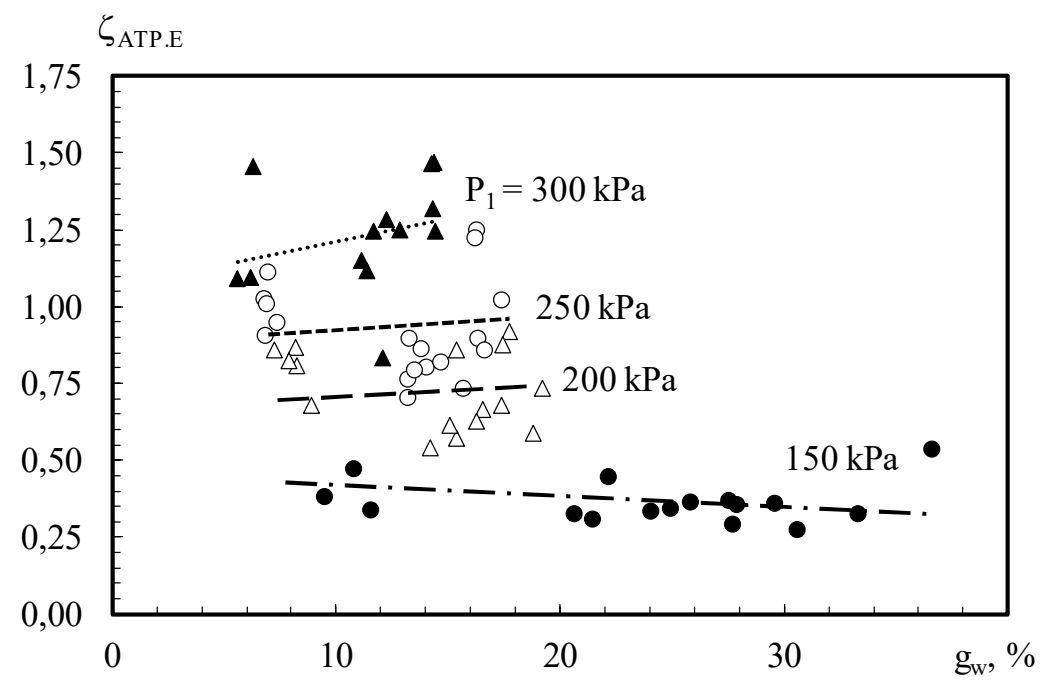

Fig. 9. Experimental dependences of the hydraulic resistance coefficient $\zeta_{\text {ATP.E }}$ on the relative flow rate of the injected water $g_{\mathrm{w}}$ at various initial pressures: $P_{1}=150 ; 200 ; 250$; $300 \mathrm{kPa}$.

Based on the obtained experimental data, the equations of the dependence of the hydraulic resistance coefficient in the aerothermopressor flow part $\zeta_{\text {ATP }}$ were determined by the approximation method according to a number of equations and depending on the initial pressure at the receiving chamber inlet $P_{1}$ and the relative water injected flow rate $g_{\mathrm{w}}$. In this case, the plane equations were selected (Fig. 10):

$$
\zeta_{\text {ATP }}=0.0983 \cdot g_{\mathrm{w}}+5.8633 \cdot 10^{-6} \cdot P_{1}-0.5004
$$

This equation (regression coefficient $-\mathrm{R}=0.8847 ; \mathrm{R}^{2}=0.7827$ ) is obtained for the following characteristics of the aerothermopressor operation: $1.2 \cdot 10^{5}<\operatorname{Re}<3.4 \cdot 10^{5}$; $M=0.25-0.65 ; g_{\text {w }}=0.05-0.35 ; P_{1}=150-300 \mathrm{kPa}$.

The deviation of the calculated values of the hydraulic resistance coefficient $\zeta_{\text {ATP.C }}$ (equation (8)) from those obtained during the experimental study $\zeta_{\text {ATP.E }}$ is $\delta_{\zeta}= \pm 25 \%$ (Fig. 11). Based on the calculated values $\zeta_{\text {ATP.C }}$, the absolute pressure loss in the aerothermopressor $\Delta P_{\text {r.C }}$ was determined (equation (1)) and their comparison with experimental $\Delta P_{\text {r.E }}$ was carried out. In this case, the deviation of the calculated data with the experimental ones was no more than $\delta_{\triangle P}= \pm 25 \%$ (Fig. 12). This indicates that the empirical dependence (8) for determining $\zeta_{\text {ATP }}$ can be applied to the considered conditions when designing aerothermopressor for gas turbine cyclic air cooling. But it should be noted that experimental data were obtained only at air flow rates to $0.52 \mathrm{~kg} / \mathrm{s}$, i.e., it is possible to 
apply the obtained dependence only for the low-flow aerothermopressor with small diameters of the evaporation chamber.

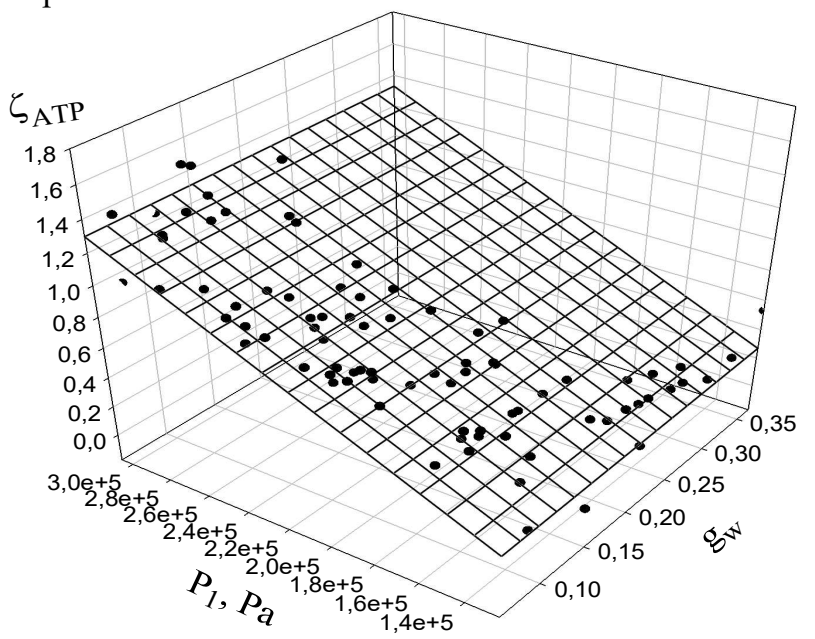

Fig. 10. Experimental dependences of the hydraulic resistance coefficient $\zeta_{\text {ATP.E }}$ on the relative flow rate of the injected water $g_{\mathrm{w}}$ at various initial pressures $P_{1}$ (distribution over the surface in accordance with equation (8))

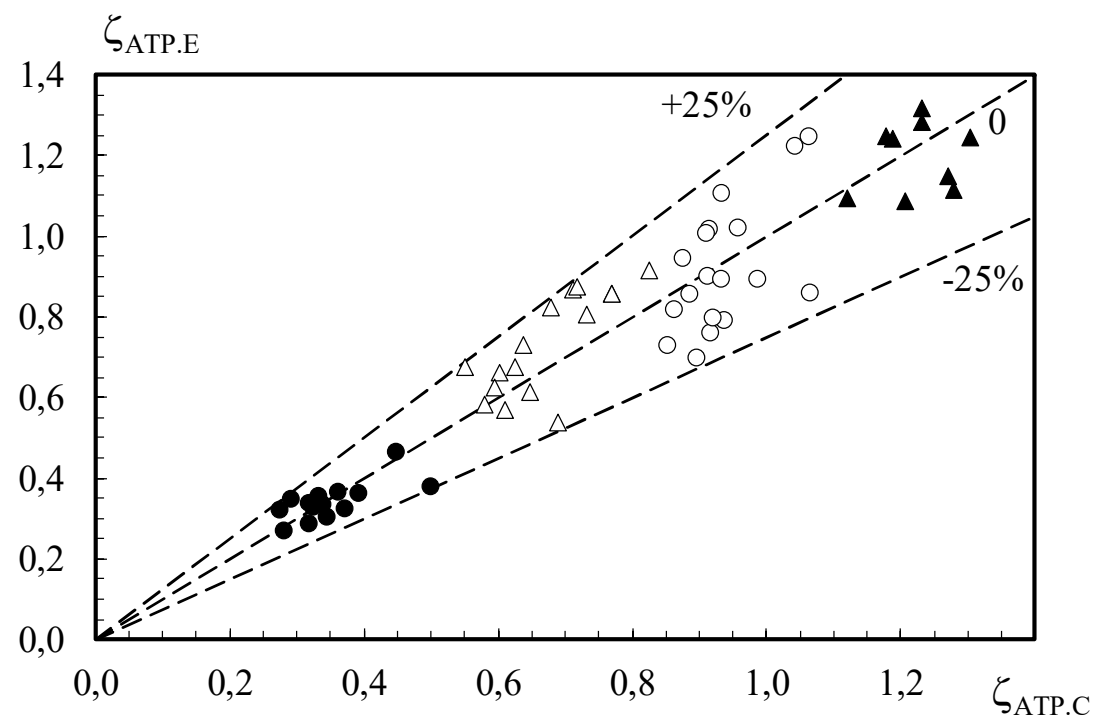

Fig. 11. Comparison of the hydraulic resistance coefficient calculated values $\zeta_{\text {ATP.C }}$ in the aerothermopressor flow part (equation (8)) with the experimental $\zeta_{\text {ATP.E }}$ 


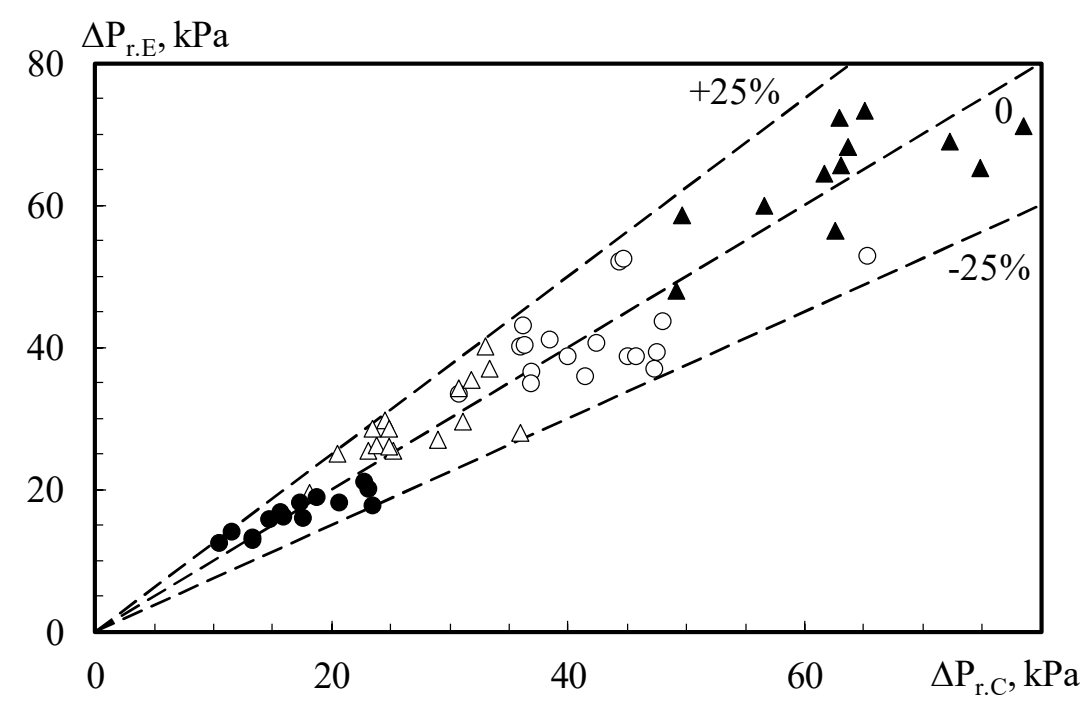

Fig. 12. Comparison of calculated pressure losses values in the aerothermopressor flow part $\Delta P_{\text {r.C }}$ with experimental $\Delta P_{\text {r.E }}$

\section{Conclusions}

The data on hydraulic resistance coefficients for the flow part of the low-flow aerothermopressor were determined experimentally. The experimental hydraulic resistance coefficient $\zeta_{\text {ATP.E }}=0.35-1.30$, depending on the initial pressure $P_{1}$, and the relative flow rate $g_{\mathrm{w}}$ of water injected into the inlet chamber has been received. The absolute values of pressure losses were $\Delta P_{\mathrm{r}}=18-75 \mathrm{kPa}(11-24 \%)$.

An empirical equation was proposed to determine the hydraulic resistance coefficient of the aerothermopressor flow part $\zeta_{\text {ATP }}$, depending on the amount of water injected. This coefficient takes into account hydraulic losses: local losses in the confuser and diffuser; friction losses in the evaporation chamber; losses due to resistance of water droplets. The deviation of the calculated hydraulic resistance coefficient $\zeta_{\text {ATP.C }}$ from the experimental ones $\zeta_{\text {ATP.E }}$ is $\delta_{\zeta}= \pm 25 \%$. The deviation of the calculated pressure loss $\Delta P_{\mathrm{r}}$ from experimental is $\delta_{\Delta \mathrm{P}}= \pm 25 \%$. This indicates the possibility of applying this dependence under the conditions: $1.2 \cdot 10^{5}<R e<3.4 \cdot 10^{5} ; M=0.25-0.65$.

The results can be used in the practice of designing the low-flow aerothermopressors for contact air cooling.

\section{References}

1. Radchenko, A., Radchenko, M., Konovalov, A., Zubarev, A.: Increasing electrical power out-put and fuel efficiency of gas engines in integrated energy system by absorption chiller scavenge air cooling on the base of monitoring data treatment. In: Proceedings of E3S Web of Conferences 70, 03011, p. 6. HTRSE-2018 (2018).

2. Kumar, T. A., Muzaffarul, H. M., Islam, M.: Effect of ambient temperature on the performance of a combined cycle power plant. Transactions of the Canadian Society for Mechanical Engineering 37(4), 1177-1188 (2013). 
3. Eidan, A. A., Alwan, K. J.: Enhancement of the Performance Characteristics for AirConditioning System by Using Direct Evaporative Cooling in Hot Climates. Energy Procedia 142, 3998-4003 (2017).

4. Günnur, S. G. et al.: The effect of ambient temperature on electric power generation in natural gas combined cycle power plant-A case study. Energy Reports 4, 682-690 (2018).

5. Jonsson, M., Yan, J.: Humidified gas turbines - a review of proposed and implemented cycles. Energy 30, 1013-1078 (2005).

6. Boyce, M. P.: Gas Turbine Engineering Hand-book. Gulf Publishing Company, Houston, Texas (2002).

7. Elbel, S., Lawrence, N.: Review of recent developments in advanced ejector technology. International Journal of Refrigeration 62, 1-18 (2016).

8. Elbel, S.: Historical and present developments of ejector refrigeration systems with emphasis on transcritical carbon dioxide air-conditioning applications. International Journal of Refrigeration 34(7), 1545-1561 (2011).

9. Elbel, S., Hrnjak, P.: Ejector refrigeration: an overview of historical and present developments with an emphasis on air-conditioning applications (2008).

10. Lawrence, N., Elbel, S.: Theoretical and practical comparison of two-phase ejector refrigeration cycles including First and Second Law analysis. International Journal of Refrigeration 36(4), 1220-1232 (2013).

11. Konovalov, D., Kobalava, H.: Efficiency Analysis of Gas Turbine Plant Cycles with Water Injection by the Aerothermopressor. In: Ivanov V. et al. (eds.) Advances in Design, Simulation and Manufacturing II. DSMIE 2019. Lecture Notes in Mechanical Engineering, pp. 581-591. Springer, Cham (2020).

12. Fowle, A.: An experimental investigation of an aerothermopressor having a gas flow capacity of 25 pounds per second. Massachusetts Institute of Technology, USA (1972).

13. Stepanov, I. R., Chudinov, V. I.: Some Problems of Gas and Liquid Motion in the Channels and Pipelines of Power Plants. The Science Publ., Leningrad (1977).

14. Zhivitsa, V. I.: Intercoolers with thermopressor for two-stage ammonia refrigeration machines. Refrigeration Engineering 5, pp. 18-20 (2002).

15. Radchenko, M., Radchenko, R., Ostapenko, O., Zubarev, A., Hrych, A.: Enhancing the utilization of gas engine module exhaust heat by two-stage chillers for combined electricity, heat and refrigeration. In: Proceedings of 5th International Conference on Systems and Informatics, ICSAI 2018, pp. 240-244. Jiangsu, Nanjing, China (2019).

16. Shapiro, A. H., et al.: The Aerothermopressor - a Device for Improving the Performance of a Gas-Turbine Power Plant. In: Proceedings of the Trans. ASME, pp. 617-653. Cambridge, USA (1956).

17. Erickson, J.: A theoretical and experimental investigation of the aerothermopressor process. Massachusetts Institute of Technology, USA (1958).

18. Radchenko R., Radchenko A., Serbin S., Kantor S., Portnoi B. Gas turbine unite inlet air cooling by using an excessive refrigeration capacity of absorption-ejector chiller in booster air cooler. In: Proceedings of E3S Web of Conferences 70, 03012, 6 p. HTRSE2018 (2018).

19. Lockhart, R. W., Martinelli, R. C.: Proposed correlation of data for isothermal twophase, two-component flow in pipes. Chem. Eng. Progr. 45(1), 39-48 (1949).

20. Martinelli, R. C., Nelson, D. B.: Prediction of pressure drop during forced - circulation boiling of water. Trans. ASME 70, 695-702 (1948).

21. Dolinsky, A. A., Ivanitsky, G. K.: Heat and mass transfer and hydrodynamics in vaporliquid dispersed flow. Naukova Dumka, Kyiv (2008).

22. Kulinchenko, V. R.: Hydraulics, hydraulic machines and hydraulic drive. Tsentr navchalnoi literatury Publ., Kyiv (2006). 
23. Konovalov D., Trushliakov, E., Radchenko, M., Kobalava, H., Maksymov, V.: Research of the Aerothermopressor Cooling System of Charge Air of a Marine Internal Combustion Engine Under Variable Climatic Conditions of Operation. In: Tonkonogyi V. et al. (eds.) Advanced Manufacturing Processes. InterPartner 2019. Lecture Notes in Mechanical Engineering, pp. 520-529. Springer, Cham (2020).

24. Lin, A., et al.: Evaluation of Mass Injection Cooling on Flow and Heat Transfer Characteristics for High-Temperature Inlet Air in a MIPCC Engine. International Journal of Heat and Mass Transfer 135, 620-630 (2019).

25. Radchenko, A., Bohdal, L., Zongming, Y., Portnoi, B., Tkachenko, V.: Rational designing of gas turbine inlet air cooling system. In: Tonkonogyi V. et al. (eds.) Advanced Manufacturing Processes. InterPartner 2019. Lecture Notes in Mechanical Engineering, pp. 591-599. Springer, Cham (2020). 